\title{
Pulmonary haemodynamics of the yak, cattle, and cross breeds at high altitude
}

\author{
I S ANAND, E HARRIS, R FERRARI, P PEARCE, P HARRIS
}

From the Postgraduate Institute of Medical Education and Research, Chandigarh, India; the University of Brescia, Italy; the Institute of Zoology, Zoological Society of London, London; and the Cardiothoracic Institute, London

ABSTRACT The pulmonary arterial pressure of Ladakhi yaks, at an altitude of about $4500 \mathrm{~m}$, was not 8 significantly different from that found in yaks bred at low altitude. The pulmonary arterial ${ }^{\circ}$

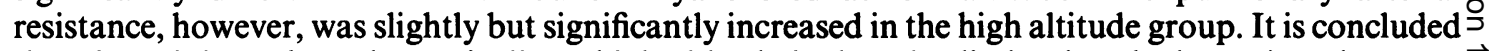
that the yak has adapted genetically to high altitude by largely eliminating the hypoxic pulmonary $\vec{C}$ vasoconstrictor response. The pulmonary arterial pressure and resistance were significantly higher $\frac{\mathbb{D}}{O}$ in indigenous Himalayan cattle than in the yaks. The dzo (cow $\times$ yak) had pulmonary haemo- $\frac{\mathbb{\mathbb { D }}}{\vec{D}}$ dynamics similar to those of the yak. Half of the stols $(\mathrm{dzo} \times$ bull) had pulmonary haemodynamics similar to those of the yak, while in the other half the findings resembled those in the cow. The results suggest that the genetic attenuation of the hypoxic vasoconstrictor response is transmitted as a simple autosomal dominant.

The evolutionary advantage of the pulmonary vasoconstrictor response to hypoxia lies probably in the reduction of the blood supply to underventilated regions of the lung, thus ensuring an equal distribution of ventilation:perfusion ratios and the maintenance of the arterial $\mathrm{Po}_{2}$. In a hypoxic environment, such as occurs at high altitude, the homeostatic necessity for equality of distribution of ventilation:perfusion ratios becomes less important owing to the shape of the oxygen dissociation curve for haemoglobin. Thus the advantages of the mechanism for natural selection are minimised. At the same time the disadvantages of hypoxic pulmonary vasoconstriction throughout the lung become manifest, and there is mortality from chronic mountain sickness and pulmonary oedema. In this way hypoxic pulmonary vasoconstriction becomes an encumbrance to survival at high altitude and adaptation by natural selection would be expected to be accompanied by a diminution or elimination of the vasoconstrictor response.

Such adaptation seems to have occurred in the Andean llama, which has thin walled pulmonary arteries $^{12}$ and a low pulmonary arterial pressure. ${ }^{3}$ Anatomical evidence suggests that adaptation has also occurred in the mountain viscacha. ${ }^{4}$

Address for reprint requests: Professor $P$ Harris, Cardiothoracic Institute, 2 Beaumont Street, London W1N 2DX.

Accepted 5 February 1986
Recently Heath and his colleagues 5 have reported that the small pulmonary arteries of the Himalayan yak also have thin walls. At first sight, such evidence $\frac{\mathscr{Q}}{\square}$ of adaptation is not surprising since the yak, like the $\underset{\vec{F}}{\overrightarrow{2}}$ llama, is well known to thrive at high altitudes. The $\frac{0}{3}$ particular interest of the yak is that it is closely related to cattle, which are known to have thick walled small pulmonary arteries ${ }^{6}$ even at sea level and which are highly susceptible to pulmonary hypertension and $\overline{0}$ "Brisket disease" at high altitude. ${ }^{7-9}$ So close is the family relation between the yak and cattle that cross $\frac{0}{0}$ breeds are common in the Himalayas.

In this series of studies we have made measurements $\delta$ of pulmonary haemodynamics at sea level in yaks and $§$ at high altitude in yaks, cattle, and various cross 0 breeds.

\section{Methods}

All animals were studied in the normal standing pos- $N$ ition without sedation. A Swan-Ganz catheter was introduced percutaneously into the jugular vein under $\sigma$ local anaesthesia and floated into the pulmonary artery. Pressures were referred to the level of the top of the humerus. The cardiac output was measured by thermodilution. Pulmonary arterial resistance was 0 calculated as the difference between mean arterial and 0 mean wedge pressures divided by the cardiac output. For statistical analysis the Wilcoxon non-parametric $\stackrel{\mathbb{D}}{\overparen{D}}$ test was used. 
After capture and during the initial part of the procedure physical restraint was necessary. But during the period when experimental data were collected the animal had usually calmed down and little restraint was required.

Six low altitude yaks were studied at the Zoological Society of London's Whipsnade Park. These animals were part of the herd of undomesticated animals.

All the high altitude studies were carried out in the vicinity of Tak Tok gompa, above the village of Shakti, Ladakh, India, at an altitude of about $4500 \mathrm{~m}$. Here we made studies on five domestic yaks and six cattle. In addition, we studied five dzos (the cross breed of cow and yak), seven stols (the cross breed of dzo and bull), and one gar (the cross breed of female dzo and male yak).

Details of the animals are given in tables 1 and 2. The indigenous breed of Ladakhi cattle was black or black-brown in colour and of a stature considerably smaller than that of lowland breeds. The domestic yak was much larger, averaging four to five times the size of the cattle. All the cross breeds had a stature similar to that of the cattle.

Apart from their smaller size, dzos preserved many

Table 1 Data from low altitude and high altitude yaks

\begin{tabular}{|c|c|c|c|c|c|c|c|c|}
\hline Animal & Sex & $\begin{array}{l}\text { Age } \\
(y)\end{array}$ & $\begin{array}{l}\text { Heart rate } \\
(/ \min )\end{array}$ & $\begin{array}{l}\text { Right } \\
\text { atrial pressure } \\
(\mathrm{mm} \mathrm{Hg})\end{array}$ & $\begin{array}{l}\text { Pulmonary arterial } \\
\text { pressure ( } \mathrm{mm} \mathrm{Hg}) \text { : } \\
\text { systolic/diastolic (mean) }\end{array}$ & $\begin{array}{l}\text { Wedge } \\
\text { pressure } \\
\text { (mm Hg) }\end{array}$ & $\begin{array}{l}\text { Cardiac } \\
\text { output } \\
\text { (l/min })\end{array}$ & $\begin{array}{l}\text { Pulmonary arterial } \\
\text { resistance } \\
\left(\mathrm{mm} \mathrm{Hg} l^{-1} \mathrm{~min}\right)\end{array}$ \\
\hline \multicolumn{9}{|c|}{ Sea level yak } \\
\hline 1 & $\mathbf{M}$ & $>1$ & - & - & $23 / 7$ (16) & 10 & $21 \cdot 8$ & $0 \cdot 28$ \\
\hline 2 & $\mathbf{M}$ & $>1$ & - & - & $31 / 11(21)$ & 14 & $21 \cdot 2$ & $0 . \overline{33}$ \\
\hline 3 & $\mathbf{F}$ & 2 & - & - & $32 / 8$ (19) & 8 & $27 \cdot 3$ & 0.40 \\
\hline 4 & $\mathbf{F}$ & 8 & - & - & $32 / 15(21)$ & 14 & $25 \cdot 2$ & 0.30 \\
\hline 5 & $\mathbf{M}$ & 2 & 一 & - & $38 / 5$ (19) & 6 & $38 \cdot 2$ & 0.33 \\
\hline 6 & $\mathbf{F}$ & 1 & - & - & $29 / 11(19)$ & 12 & 18.6 & 0.39 \\
\hline Mean & & & & & $31 / 10(19)$ & 11 & $25 \cdot 4$ & 0.34 \\
\hline \multicolumn{9}{|c|}{ High altitude yak } \\
\hline 1 & $\mathbf{M}$ & 12 & 53 & -2 & $26 / 13(18)$ & 7 & $24 \cdot 1$ & 0.48 \\
\hline 2 & $\mathbf{M}$ & 13 & 52 & 0 & $30 / 15(21)$ & 8 & $25 \cdot 4$ & 0.51 \\
\hline 3 & $\mathbf{M}$ & 12 & 50 & 0 & $28 / 18(22)$ & 11 & $22 \cdot 2$ & 0.51 \\
\hline 4 & $\mathbf{M}$ & 13 & 46 & - & $32 / 14(20)$ & 8 & $21 \cdot 4$ & 0.55 \\
\hline 5 & $\mathbf{M}$ & 8 & 64 & -7 & $27 / 14(20)$ & 2 & $21 \cdot 2$ & 0.87 \\
\hline Mean & & & 53 & -2 & $29 / 15(20)$ & 7 & $22 \cdot 9$ & 0.58 \\
\hline
\end{tabular}

Table 2 Data from high altitude cattle, dzos, stols, and one gar

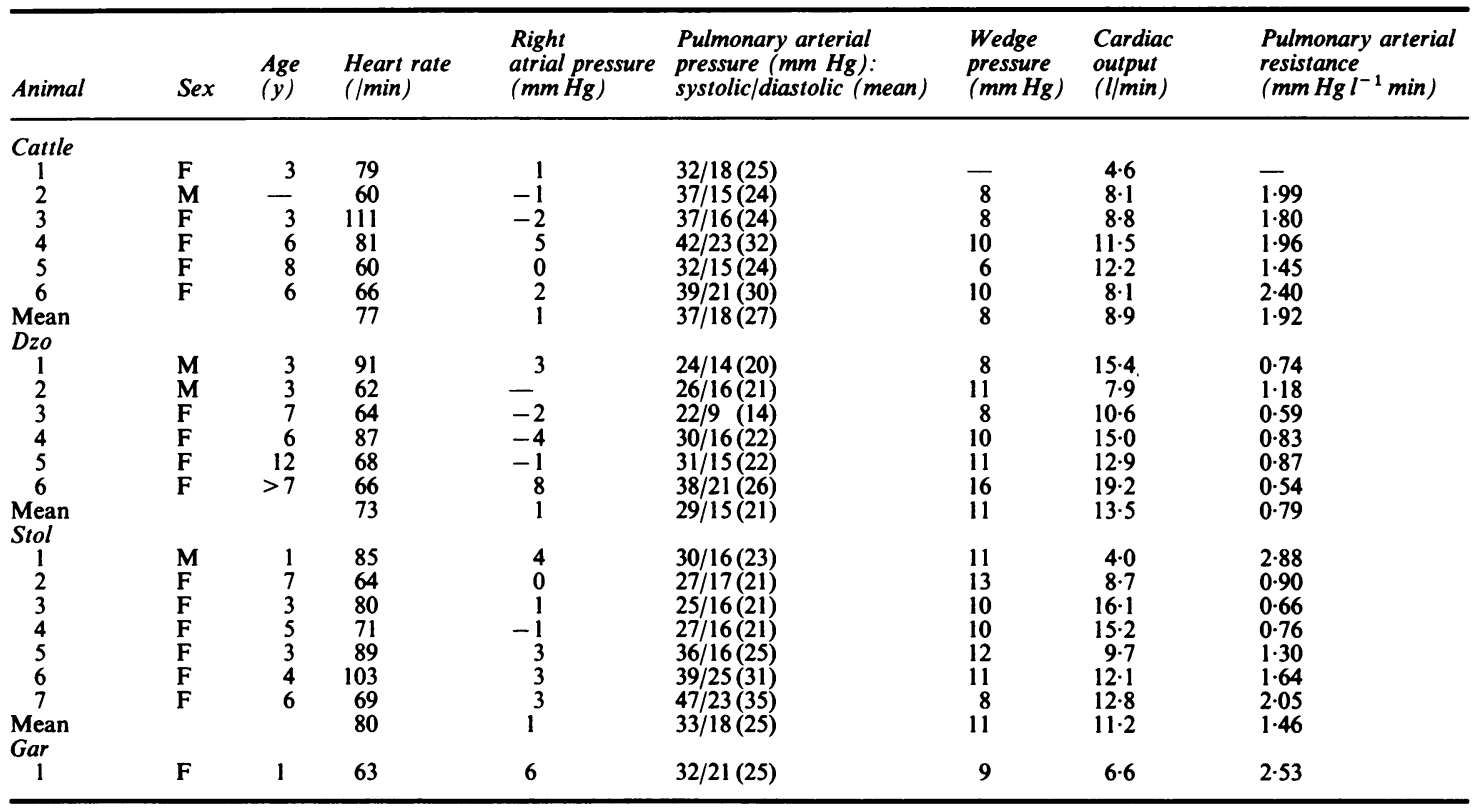


of the external characteristics of the yak. Their horns curved upwards, as in the yak; they had the yak's short, bushy tail; and shaggy hair hung from the belly half way down the leg. They made the short, grunting sound of the yak.

Stols resembled cows more closely. Their horns curved downwards. Their tails were long and thin, extending down to the hoof. The hair was less shaggy and did not hang down from the belly. They mooed like cows.

\section{Results}

Table 1 shows the results obtained in low and high altitude yaks. The two groups had similar values for the pulmonary arterial pressure and the cardiac output, while the wedge pressure tended to be lower in the Himalayan group. The mean (SD) pulmonary arterial resistance was $0.34(0.05) \mathrm{mm} \mathrm{Hgl}^{-1} \mathrm{~min}$ in the low altitude group and $0.58(0.16) \mathrm{mm} \mathrm{Hgl}^{-1} \mathrm{~min}$ in the high altitude group $(\mathrm{p}<0.01)$.

Table 2 gives details of the high altitude cattle, dzos, stols, and one gar. The average mean pulmonary arterial pressure in cattle was $27 \mathrm{~mm} \mathrm{Hg}$, compared with $20 \mathrm{~mm} \mathrm{Hg}$ in the high altitude yaks $(\mathrm{p}<0.01)$. There was no difference in wedge pressure between these two groups. The cardiac output of the cattle was only about $40 \%$ of that of the yaks $(\mathrm{p}<0.01)$. The average pulmonary arterial resistance was $1.92(0.34) \mathrm{mm} \mathrm{Hg}^{-1} \mathrm{~min}$ in the cattle $(\mathrm{p}<0.01$ for cattle $v$ yaks).

The data for the dzos resemble those of the high altitude yaks much more than those of the cattle. The average mean pulmonary arterial pressure was $21 \mathrm{~mm} \mathrm{Hg}$ in the dzos $(\mathrm{p}<0.05$ for comparison with cattle). The cardiac output of the dzos tended to be higher than that of the cattle, while the average pulmonary arterial resistance of the dzos was $0.79 \mathrm{~mm} \mathrm{Hgl}^{-1} \mathrm{~min}(\mathrm{p}<0.01$ for comparison with cattle).

The data for the stols are considerably dispersed. Roughly half of them had pulmonary arterial pressures and resistances similar to those found in cattle, while in the remainder the values were similar to those of the yaks.

\section{Discussion}

\section{COMPARISON BETWEEN LOW AND HIGH}

ALTITUDE YAKS

Although the pulmonary arterial pressure of the high altitude yaks was almost the same as that of the low altitude yaks, the measurement of resistance showed a small but significant increase in the high altitude group. This indicates that the hypoxic pulmonary vasoconstrictive response is greatly diminished but not entirely eliminated. A similar slight but significant difference was noted between the pulmonary arterial $\underset{\vec{S}}{\stackrel{\vec{S}}{S}}$ pressures of low and high altitude llamas. ${ }^{3}$

\section{HIMALAYAN CATTLE}

The indigenous Himalayan cattle are smaller and $\overparen{\varnothing}$ quite distinct in appearance from the domestic breeds that are a well known feature of the lowlands of India. 2 The mean pulmonary arterial pressure in the Hima- $\vec{\circ}$ layan cattle averaged $27 \mathrm{~mm} \mathrm{Hg}$, which is similar to $\overrightarrow{\vec{\omega}}$ that reported by Reeves $e t a^{10}$ in Hereford steers at an ${ }_{\sigma}^{\omega}$ altitude of $1520 \mathrm{~m}$. The zero reference level used by $\vec{x}$ these authors was different, however, leading to a wedge pressure of $13 \mathrm{~mm} \mathrm{Hg}$, compared with an aver- $\overrightarrow{0}$ age value of $8 \mathrm{~mm} \mathrm{Hg}$ in our animals. Thus the mean pulmonary arterial pressure of the Herefords, taken from our zero reference point, may be expected to be $\circ$ in the region of $22 \mathrm{~mm} \mathrm{Hg}$. The pulmonary arterial resistance of the Herefords at $1520 \mathrm{~m}$ averaged $c s$ $0.43 \mathrm{~mm} \mathrm{Hgl}^{-1} \mathrm{~min}$, which is only a quarter of that $\frac{\mathbb{D}}{0}$ calculated in the Himalayan cattle.

While these figures indicate a degree of pulmonary $\frac{3}{\sigma}$ vasoconstriction in the Himalayan cattle, this is less $\mathbb{D}$ than would be expected from the studies on Herefords $\vec{\varphi}$ transported to high altitude. ${ }^{1011}$ The average mean pulmonary arterial pressure of 10 Herefords after eight weeks at an altitude of $3870 \mathrm{~m}$ was as high as $73 \mathrm{~mm} \mathrm{Hg} .{ }^{10}$ It seems likely therefore that the strain of cattle established in Ladakh over many generations is itself partly adapted.

\section{COMPARISON BETWEEN HIMALAYAN CATTLE} AND YAKS

The pulmonary arterial resistance in cattle was more than three times that in yaks. This difference is partly attributable to the difference in magnitude of the car- $\overrightarrow{0}$ diac output. The indigenous Himalayan cattle were much smaller than the yaks. We were unable to weigh $\underset{-}{\times}$ the animals in the field, but we made approximate 3 . estimates of their volume by measuring their length and girth and calculating the volume contained in a cylinder of these dimensions. Estimates suggested that the yaks were about four times the size of the cows. The average volume of the yaks was $0.61 \mathrm{~m}^{3}$ while the average volume of the cows was $0 \cdot 15 \mathrm{~m}^{3}$. We cannot therefore be sure to what extent the differences in $N$ resistance are simply an expression of a difference in size. On the other hand, the pulmonary arterial pressure was itself considerably higher in the cattle while ${ }^{\omega}$ the level of the pulmonary arterial pressure at sea levelo does not vary greatly among mammals of widelye diverse sizes. ${ }^{12}$

\section{Dzos}

In dzos, a cross breed of cows and yaks, the pulmonary arterial pressure and pulmonary arteria $\stackrel{P}{\mathbb{D}}$ resistance resembled those of the yaks and not those 


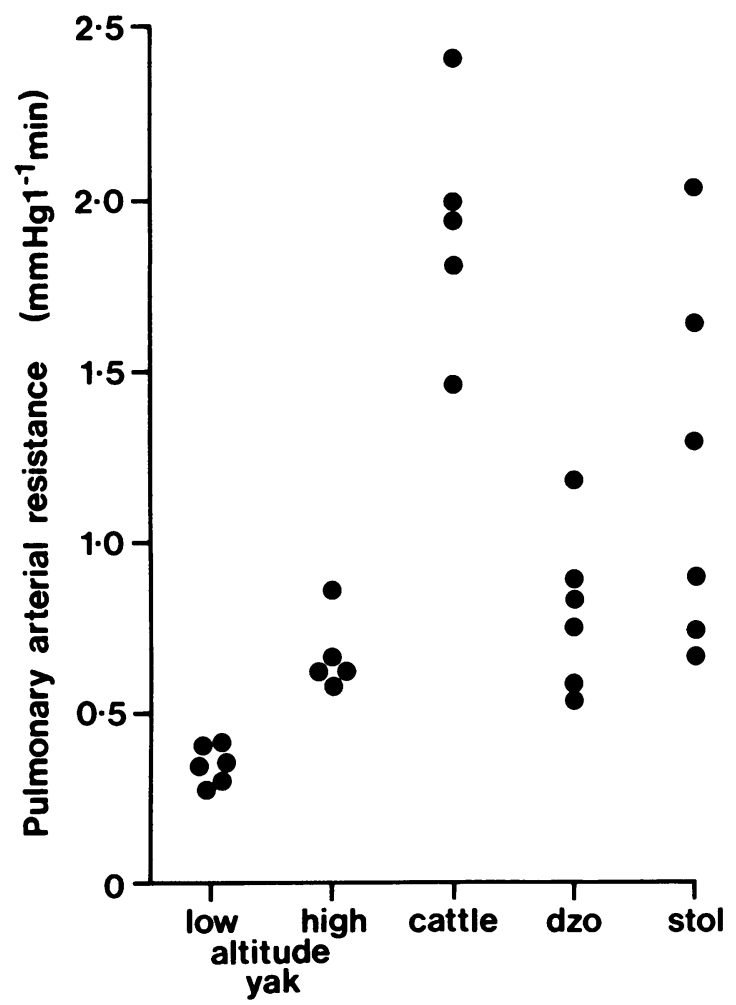

Pulmonary arterial resistance in low and high altitude yaks and high altitude adult cattle, dzos, and stols.

of the cattle. The dzos were similar in stature to the cattle, our estimates of volume making the dzos on average $0.20 \mathrm{~m}^{3}$-only $30 \%$ larger than the cattle. Thus the differences between dzos and cattle are not obscured by differences in size.

Taking the evidence so far, therefore, we may conclude that the yak has adapted by greatly attenuating the hypoxic vasoconstrictive response and that this trait is transmitted in a dominant fashion.

\section{STOLS}

For the stols (a cross breed of dzo and bull) the data separate in a fashion suggesting simple Mendelian inheritance. About half the stols resemble cattle, having presumably received the "cattle" alleles in duplicate; while the other half resemble yaks, having presumably received one "cattle" and one (dominant) "yak" allele. The stature of the stols was about the same as that of the cattle (average volume $0.13 \mathrm{~m}^{3}$ ), so that questions of size again do not complicate the issue.

If this interpretation is correct, one would expect the gar (dzo mother and yak father) to have predominantly yak characteristics. In fact, the pulmonary arterial pressure and resistance of this animal resem- bled closely those of the cattle. The animal was, however, only about 1 year old. The fall in pulmonary arterial pressure after birth is known to be delayed at high altitude, measurements in children under 5 years of age averaging $45 \mathrm{~mm} \mathrm{Hg} .{ }^{13}$ The Wagenvoorts ${ }^{14}$ noted a diminution of the thickness of the pulmonary arterial walls in sea level cattle after the age of 1 year. It is possible therefore that in this young animal we are seeing the effects of a delayed involution of the musculature of the pulmonary arterial tree that is common to many species. The only other animal of this age was a stol, whose pulmonary arterial resistance was also raised.

\section{GENETIC FACTORS}

Genetic factors have most convincingly been demonstrated to be important by Weir et al. ${ }^{15}$ From cattle residing at an altitude of $3000 \mathrm{~m}$ they selected two groups: one with a relatively low pulmonary arterial pressure and one with a high pressure. Each group was then removed to low altitude and the animals were bred within each group. On return to high altitude both the first and the second generation offspring retained the responses of the original groups.

The present observations, summarised in the figure, confirm and extend these findings. They provide evidence that the loss of the hypoxic vasoconstrictor response in an adapted high altitude species is transmitted genetically. Although the findings could be explained on a polygenic basis, the segregation suggests the pattern of a single autosomal dominant. Further breeding experiments would be needed to establish beyond doubt that the trait is under the control of a single locus.

This work was supported by a grant from the Nuffield Foundation. We wish to thank Mr OP Narankari for the technical help provided.

\section{References}

1 Heath D, Castillo Y, Arias-Stella J, Harris P. The small pulmonary arteries of the llama and other domestic animals native to high altitudes. Cardiovasc Res 1969;3:75-8.

2 Heath D, Smith P, Williams D, Harris P, Arias-Stella J, Krüger $H$. The heart and pulmonary vasculature of the llama (Lama glama). Thorax 1974;29:463-71.

3 Harris P, Heath D, Smith P, et al. The pulmonary circulation of the llama at high and low altitudes. Thorax $1981 ; 37: 38-45$.

4 Heath D, Williams D, Harris P, Smith P, Krüger $H$, Ramirez A. The pulmonary vasculature of the mountain-viscacha (Lagidium peruanum). The concept of adapted and acclimatized vascular smooth muscle. J Comp Pathol 1981;91:293-301.

5. Heath..D, Williams D, Dickinson J. The pulmonary arteries of the yak. Cardiovasc Res 1984;18:133-9. 
6 Best PV, Heath D. Interpretation of the appearances of the small pulmonary blood vessels in animals. Circ Res 1961;9:288-94.

7 Alexander AF. The bovine lung: normal vascular histology and vascular lesions in high mountain disease. Med Thorac 1962;19:528-42.

8 Hecht HH, Lange RL, Carnes WH, Kuida H, Blake JT. Brisket Disease. I. General aspects of pulmonary hypertensive heart disease in cattle. Trans Ass Am Physn 1959;72:157-72.

9 Hecht HH, Kuida H, Lange RL, Thorne JL, Brown AM. Brisket Disease. II. Clinical features and hemodynamic observations in altitude-dependent right heart failure in cattle. Am J Med 1962;32:171-83.

10 Reeves JT, Grover RF, Will DH, Alexander AF. Hemodynamics in normal cattle. Circ Res 1962;10:166-71.
11 Will DH, Alexander AF, Reeves JT, Grover RF. High $\stackrel{\vec{F}}{\stackrel{\vec{S}}{9}}$ altitude induced pulmonary hypertension in normal cattle. Circ Res 1962;10:172-7.

12 Harris $\mathrm{P}$, Heath $\mathrm{D}$. The human pulmonary circulation. 3rd ed. Edinburgh: Churchill Livingstone, 1986.

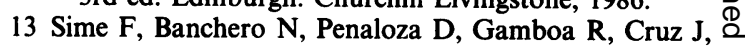
Marticorena E. Pulmonary hypertension in children कै born and living at high altitudes. Am J Cardiol 1963;11:143-9.

14 Wagenvoort CA, Wagenvoort $\mathrm{N}$. The pulmonary vasculature in normal cattle at sea level at different ages. Pathol Eur 1969;4:265-73.

15 Weir EK, Tucker A, Reeves JT, Will DH, Grover RF. The genetic factor influencing pulmonary hypertension in cattle at high altitudes. Cardiovasc Res 0 1974;8:745-9. 